\title{
Xanthine Oxidase Produces Hydrogen Peroxide which Contributes to Reperfusion Injury of Ischemic, Isolated, Perfused Rat Hearts
}

\author{
James M. Brown, Lance S. Terada, Michael A. Grosso, Glenn J. Whitmann, Stephen E. Velasco, \\ Anita Patt, Alden H. Harken, and John E. Repine \\ Departments of Surgery and Medicine and the Webb-Waring Lung Institute at the University of Colorado \\ Health Sciences Center, Denver, Colorado 80262
}

\begin{abstract}
Three lines of investigation indicated that hydrogen peroxide $\left(\mathrm{H}_{2} \mathrm{O}_{2}\right)$ from xanthine oxidase (XO) contributes to cardiac dysfunction during reperfusion after ischemia. First, addition of dimethylthiourea (DMTU), a highly permeant $\mathrm{O}_{2}$ metabolite scavenger (but not urea) simultaneously with reperfusion improved recovery of ventricular function as assessed by ventricular developed pressure (DP), contractility $(+\mathrm{d} P / \mathrm{d} t)$, and relaxation rate $(-\mathrm{d} P / \mathrm{d} t)$ in isolated Krebs-Henseleit-perfused rat hearts subjected to global normothermic ischemia. Second, hearts from rats fed tungsten or treated with allopurinol had negligible $\mathrm{XO}$ activities $(<0.5 \mathrm{mU} / \mathrm{g}$ wet myocardium compared with $>6.0 \mathrm{mU} / \mathrm{g}$ in control hearts) and increased ventricular function after ischemia and reperfusion. Third, myocardial $\mathrm{H}_{2} \mathrm{O}_{2}$-dependent inactivation of catalase occurred after reperfusion following ischemia, but not after ischemia without reperfusion or perfusion without ischemia. In contrast, myocardial catalase did not decrease during reperfusion of ischemic hearts treated with DMTU, tungsten, or allopurinol.
\end{abstract}

\section{Introduction}

Although ischemic heart disease remains a leading cause of death, recent advances in techniques that reestablish blood flow have raised hope regarding improved salvage of ischemic myocardium $(1,2)$. However, along with these advances has come concern regarding the existence and causes of injury produced by reperfusion. A role for xanthine oxidase $(\mathrm{XO})^{1}-$ derived $\mathrm{O}_{2}$ metabolites (3-5) has been suggested, but a number of crucial aspects remain unknown. In particular, the nature, timing, source, and significance of $\mathrm{O}_{2}$ metabolites have not been fully determined, in part because of the complexity of

Address correspondence and reprint requests to Dr. James M. Brown, Box C322, 4200 East Ninth Avenue, Denver CO 80262. Received for publication 11 December 1987.

1. Abbreviations used in this paper: DMTU, dimethylthiourea; DP, developed pressure; $\mathrm{XO}$, xanthine oxidase.

J. Clin. Invest.

(c) The American Society for Clinical Investigation, Inc.

$0021-9738 / 88 / 04 / 1297 / 05 \quad \$ 2.00$

Volume 81, April 1988, 1297-1301 studies in intact animal models and human subjects. We addressed these issues by hypothesizing that generation of hydrogen peroxide $\left(\mathrm{H}_{2} \mathrm{O}_{2}\right)$ by XO during reperfusion contributes to cardiac reperfusion injury. We tested this premise in simplified ("blood-free") isolated hearts using dimethylthiourea (DMTU), a highly permeant $\mathrm{O}_{2}$ metabolite scavenger, infused only during reperfusion (6). We also assessed the effect of inhibiting XO (by HPLC analysis) with tungsten (7-9) or allopurinol (10) on ventricular function after ischemia and reperfusion. In addition, we measured $\mathrm{H}_{2} \mathrm{O}_{2}$-dependent aminotriazole inactivation of myocardial catalase activity as an indicator of myocardial $\mathrm{H}_{2} \mathrm{O}_{2}$ production $(11,12)$.

\section{Methods}

Preparation and measurement of injury in isolated hearts. Healthy, male Sprague-Dawley rats $(300-325 \mathrm{~g})$ were anesthetized $(60 \mathrm{mg} / \mathrm{kg}$ i.p. sodium pentobarbital) and heparinized (500 $\mathrm{U}$ via right atrium). Hearts were rapidly excised and then perfused $(70 \mathrm{mmHg}$ ) in retrograde fashion at the aortic root with a Krebs-Henseleit solution containing $1.2 \mathrm{mM}\left[\mathrm{Ca}^{2+}\right], 4.7 \mathrm{mM}[\mathrm{KCl}]$, and $25.0 \mathrm{mM}\left[\mathrm{NaHCO}_{3}\right]$ on a modified Langendorff apparatus (13). A gas mixture $\left(92.5 \% \mathrm{O}_{2} / 7.5 \%\right.$ $\mathrm{CO}_{2}$ ) was used (Shirley Membrane), which achieved a $\mathrm{PO}_{2}=450, \mathrm{PCO}_{2}$ $=40$, and $\mathrm{pH}=7.4$. A water-filled latex balloon was placed through the left atrium into the left ventricle, secured with an atrial 6-0 silk purse string suture and adjusted to a left ventricular end diastolic pressure of $6 \mathrm{mmHg}$. Pacing wires (rate 300 beats per minute; turned off during ischemia) were attached to the pulmonary outflow tract. After equilibration for $15 \mathrm{~min}$, ventricular developed pressure (DP) and the positive $(+\mathrm{d} P / \mathrm{d} t)$ and negative $(-\mathrm{d} P / \mathrm{d} t)$ first derivatives were recorded using direct pressure and differentiator amplifiers. Subsequently, hearts were subjected to global normothermic $\left(37^{\circ} \mathrm{C}\right.$ waterbath) ischemia (aortic root stopcock) and reperfusion. In some experiments , 19.2 mM DMTU (Alpha Products, Danvers, MA) or equimolar urea (Fisher Scientific, Fair Lawn, NJ) solutions (in $0.9 \% \mathrm{NaCl}$ ) were infused at the aortic root at $0.2 \mathrm{~cm}^{3} / \mathrm{min}$ simultaneously with reperfusion. No changes in $\mathrm{pH}$ or temperature occurred during infusion of DMTU or urea. Other rats were fed a low molybdenum, tungsten-enriched diet (protein impregnated with $0.7 \mathrm{~g} / \mathrm{kg}$ sodium tungstate, ICN Nutritional Biomedicals, Cleveland, $\mathrm{OH}$ ) and were given $\mathrm{H}_{2} \mathrm{O}$ with 10 ppm tungsten (Sigma Chemical Co., St. Louis, MO) for 3 wk $(5,7-9,14)$, or were treated with allopurinol (infused at aortic root, final concentration at $25 \mu \mathrm{M}$ /liter for $10 \mathrm{~min}$ ) before ischemia and then continuously during reperfusion.

Measurement of myocardial XO activity. In separate experiments, hearts were removed from the perfusion apparatus after ischemia, freeze clamped with liquid nitrogen, weighed, and homogenized in buffer containing $50 \mathrm{mM} \mathrm{KPO}_{4}, 0.2 \mathrm{M} \mathrm{Na}_{2} \mathrm{CO}_{3} / \mathrm{HCO}_{3}(\mathrm{pH}=10.0)$, 1 
mM PMSF, $1 \mathrm{mM}$ dithioerythritol, and $0.2 \mathrm{mM}$ EDTA. After centrifugation for $30 \mathrm{~min}$ at $45,000 \mathrm{~g}$, supernatants were passed over a bufferequilibrated G-25 Sephadex column of $4^{\circ} \mathrm{C}(15)$. Supernatants from allopurinol or control hearts were treated similarly, except that they were not passed over the column to prevent loss of allopurinol into the Sephadex. XO activity was determined by measuring uric acid made in the presence of xanthine and ambient $\mathrm{O}_{2}$. Calibration standards were prepared using uric acid $(5,10$, and $15 \mu \mathrm{M})$ or $50 \mu \mathrm{M}$ xanthine in buffer with PMSF, dithioerythritol, and EDTA. Samples were prepared by adding $1 \mathrm{ml}$ Sephadex effluent to buffer, $50 \mu \mathrm{M}$ buffer + xanthine, or $50 \mu \mathrm{M}$ buffer + xanthine + allopurinol. All standards and samples were incubated at $37^{\circ} \mathrm{C}$ for $1 \mathrm{~h}$ and then $1.8 \mathrm{M}$ perchloric acid was added to stop the reaction. After precipitated protein was removed by centrifugation, $10 \mu \mathrm{l}$ aliquots of supernatants were injected into the HPLC column ([Waters C-18 Resolve; Waters Associates, Millipore Corp., Milford, MA] reverse phase, with a mobile phase of $20 \mathrm{mM}$ $\mathrm{KH}_{2} \mathrm{PO}_{4}$ plus $3 \% \mathrm{MeOH}$ at $\mathrm{pH} 5.0$, at a rate of $0.7 \mathrm{ml} / \mathrm{min}$ ). Uric acid peaks were integrated at $290 \mathrm{nM}$. Specific activity was expressed as milliunits per gram wet weight of myocardium. One unit of activity equaled one micromole of uric acid made per minute.

Measurement of catalase activity after aminotriazole treatment. In separate experiments, rats were pretreated with aminotriazole (500 $\mathrm{mg} / \mathrm{kg}$ i.p.) $1 \mathrm{~h}$ before anesthetization. After study, hearts were placed immediately in $\mathrm{KPO}_{4}$ buffer $(10 \mathrm{ml}$ of $5 \mathrm{mM}$ at $\mathrm{pH}=7.8)$ and homogenized. Homogenates were centrifuged at $20,000 \mathrm{rpm}$ for $10 \mathrm{~min}$, supernatants were collected, and catalase activities were measured spectrophotometrically ( $240 \mathrm{nM})$. After adjusting the absorbance to zero, using empty quartz cuvettes for reference and sample slots, potassium phosphate Triton $\mathrm{X}$ buffer $(3 \mathrm{ml}$ of $50 \mathrm{mM}, \mathrm{pH}=7.0)$ and $\mathrm{H}_{2} \mathrm{O}_{2}$ ( $100 \mathrm{ml}$ of $50 \mathrm{mM} \mathrm{KPO}_{4}$ buffer $+135 \mu \mathrm{l}$ of $30 \% \mathrm{H}_{2} \mathrm{O}_{2}$ ) were added to reference and sample cuvettes, respectively. Absorbance was adjusted to $0.550 \mathrm{U}$ by adding $30 \% \mathrm{H}_{2} \mathrm{O}_{2}$ to the $\mathrm{KPO}_{4} / \mathrm{H}_{2} \mathrm{O}_{2}$ solution. Standards were prepared by adding a standard catalase solution $(75 \mu \mathrm{l})$ to each cuvette. Samples were prepared by adding sample supernatants $(75 \mu \mathrm{l})$ to each cuvette. Absorbance per minute was recorded and catalase activity calculated as units per gram wet weight myocardium.

Analyses of statistical significance (16). Values for ventricular function and catalase activities were compared by analysis of variance and by post hoc Student-Newman-Keuls tests for between group differences. Differences in XO activities were compared by paired $t$ tests.

\section{Results}

Effect of DMTU or urea treatment on ventricular function after ischemia and reperfusion. Measurements of ventricular function, including ventricular DP, contractility $(+\mathrm{d} P / \mathrm{d} t)$, and relaxation rate $(-\mathrm{d} P / \mathrm{d} t)$, were the same $(P>0.05)$ in all hearts studied before ischemia or $(P>0.05)$ after perfusion for 60 min without ischemia (Fig. 1). However, hearts subjected to ischemia for $20 \mathrm{~min}$ and then reperfused for $40 \mathrm{~min}$ had decreased $(P<0.05)$ ventricular function compared with hearts studied before ischemia or subjected to perfusion for $60 \mathrm{~min}$ without ischemia. In contrast, hearts subjected to ischemia and then treated with DMTU simultaneously with reperfusion had increased $(P<0.05)$ ventricular function compared with hearts subjected to ischemia and then reperfused with urea or no additions.

Effect of tungsten or allopurinol treatment on myocardial $X O$ activity and ventricular function after ischemia and reperfusion. After ischemia for $20 \mathrm{~min}$, hearts from rats treated with tungsten or allopurinol had decreased $(P<0.05) \mathrm{XO}$ activities compared with untreated hearts (Fig. 2). In addition, after ischemia for $20 \mathrm{~min}$ and reperfusion for $\mathbf{4 0} \mathrm{min}$, hearts from rats treated with tungsten or allopurinol had increased $(P$ $<0.05)$ ventricular function compared with untreated hearts (Fig. 3).
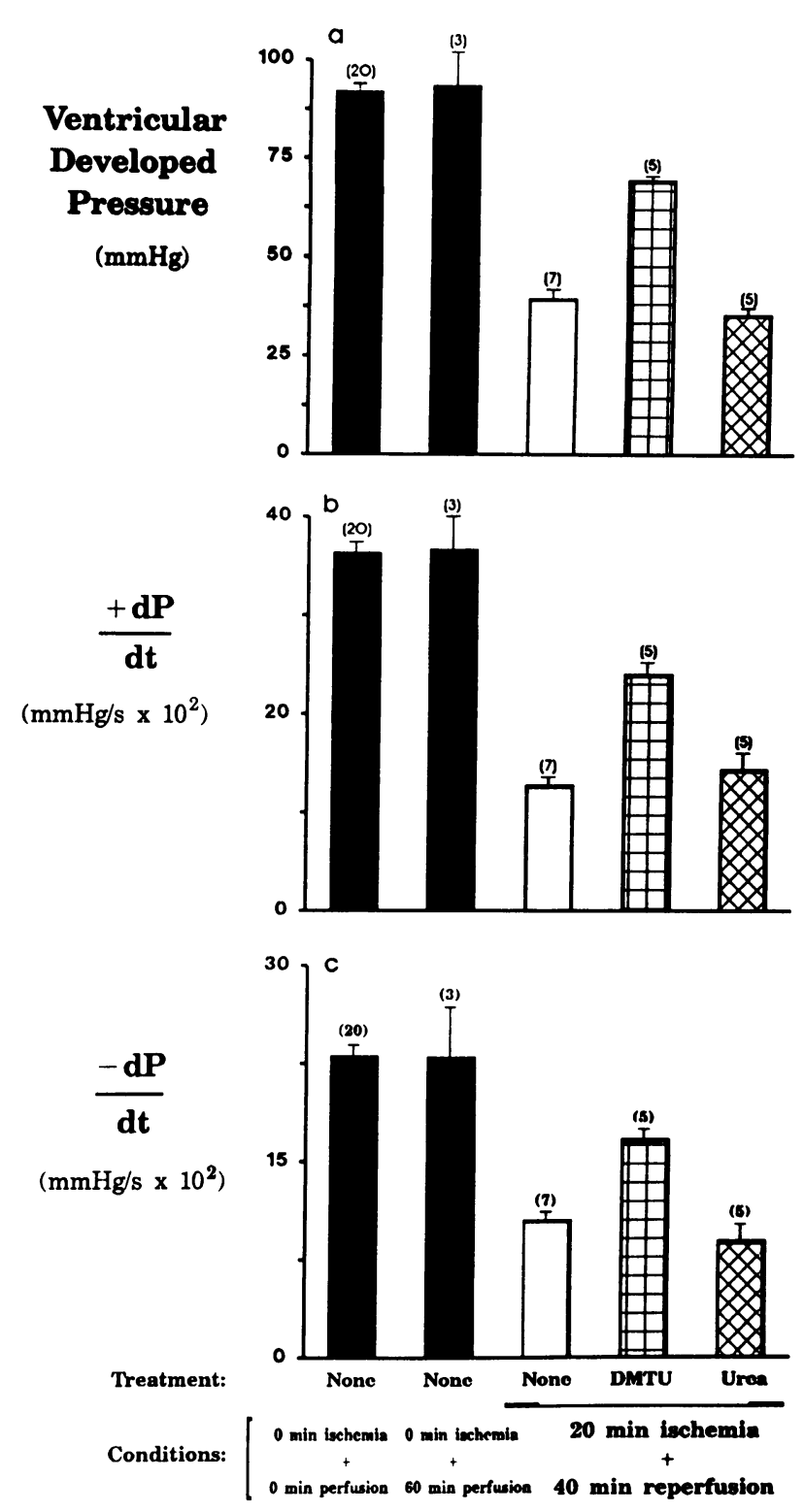

Figure 1. Ventricular function of isolated Krebs-Henseleit perfused rat hearts after global normothermic ischemia for $20 \mathrm{~min}$ and reperfusion for $40 \mathrm{~min}$. (a) Ventricular DP, $(b)$ contractility $(+\mathrm{d} P / \mathrm{d} t)$, and $(c)$ relaxation rate $(-\mathrm{d} P / \mathrm{d} t)$ were the same $(P>0.05)$ in all hearts (untreated, DMTU, or urea treated) studied before ischemia. In addition, perfusion for $60 \mathrm{~min}$ without ischemia did not change $(P$ $<0.05) \mathrm{DP},+\mathrm{d} P / \mathrm{d} t$, or $-\mathrm{d} P / \mathrm{d} t$ from preischemic values. However, after ischemia for $20 \mathrm{~min}$ and reperfusion for $40 \mathrm{~min}$, untreated hearts had decreased ventricular function compared with hearts studied before ischemia or after perfusion for $60 \mathrm{~min}$ without ischemia. In contrast, after ischemia for $20 \mathrm{~min}$ and reperfusion for $40 \mathrm{~min}$, hearts infused with $19.2 \mathrm{mM}$ DMTU $\left(0.2 \mathrm{~cm}^{3} / \mathrm{min}\right.$ at aortic root $)$ simultaneously with reperfusion had increased $(P<0.05) \mathrm{DP},+\mathrm{d} P / \mathrm{d} t$, and $-\mathrm{d} P / \mathrm{d} t$ values compared with untreated hearts or hearts infused with equimolar urea. Each bar is the mean $\pm 1 \mathrm{SE}$ of the number of determinations shown within the parentheses.

Effect of DMTU, urea, tungsten, or allopurinol treatment on myocardial catalase activities in aminotriazole-treated rats subjected to ischemia and reperfusion. Catalase activities were the same in hearts perfused for $60 \mathrm{~min}$ without ischemia or subjected to ischemia for $20 \mathrm{~min}$ without reperfusion (Fig. 4). However, when subjected to ischemia for $20 \mathrm{~min}$ and then 


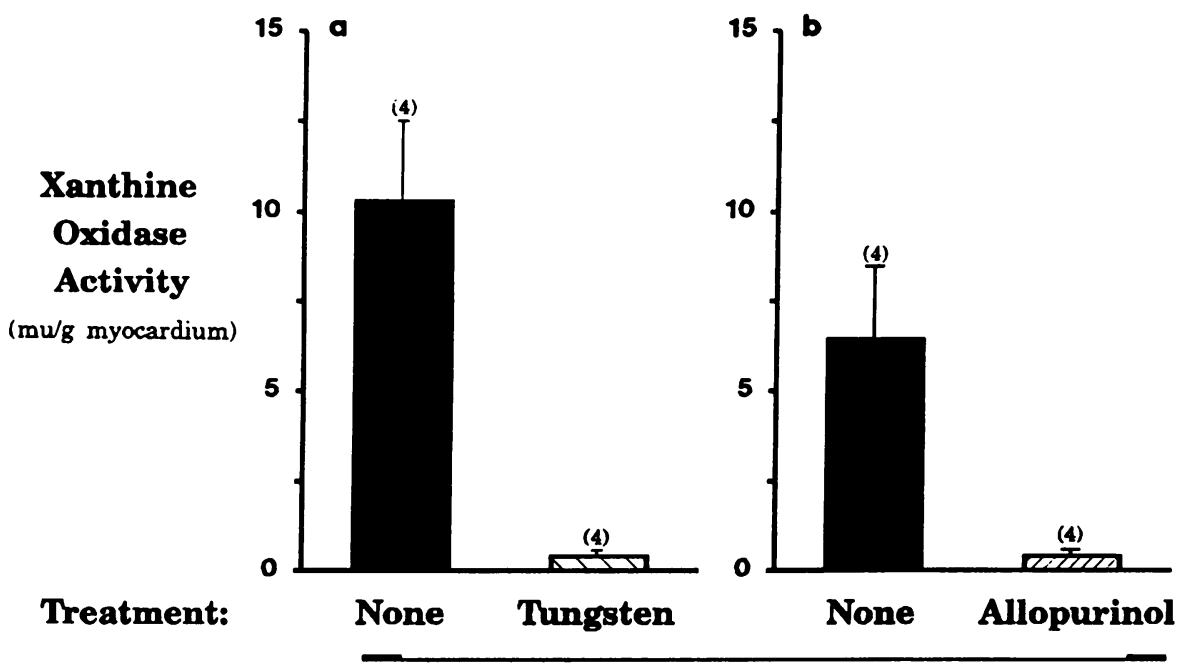

Conditions:
$20 \mathrm{~min}$ ischemia
Figure 2. Myocardial XO activity (milliunits per gram myocardium) after global normothermic ischemia for $20 \mathrm{~min}$ (before reperfusion). (a) Treatment with tungsten or $(b)$ allopurinol decreased $(P<0.05)$ myocardial XO activities. Each bar is the mean $\pm 1 \mathrm{SE}$ of the number of determinations shown within the parentheses.

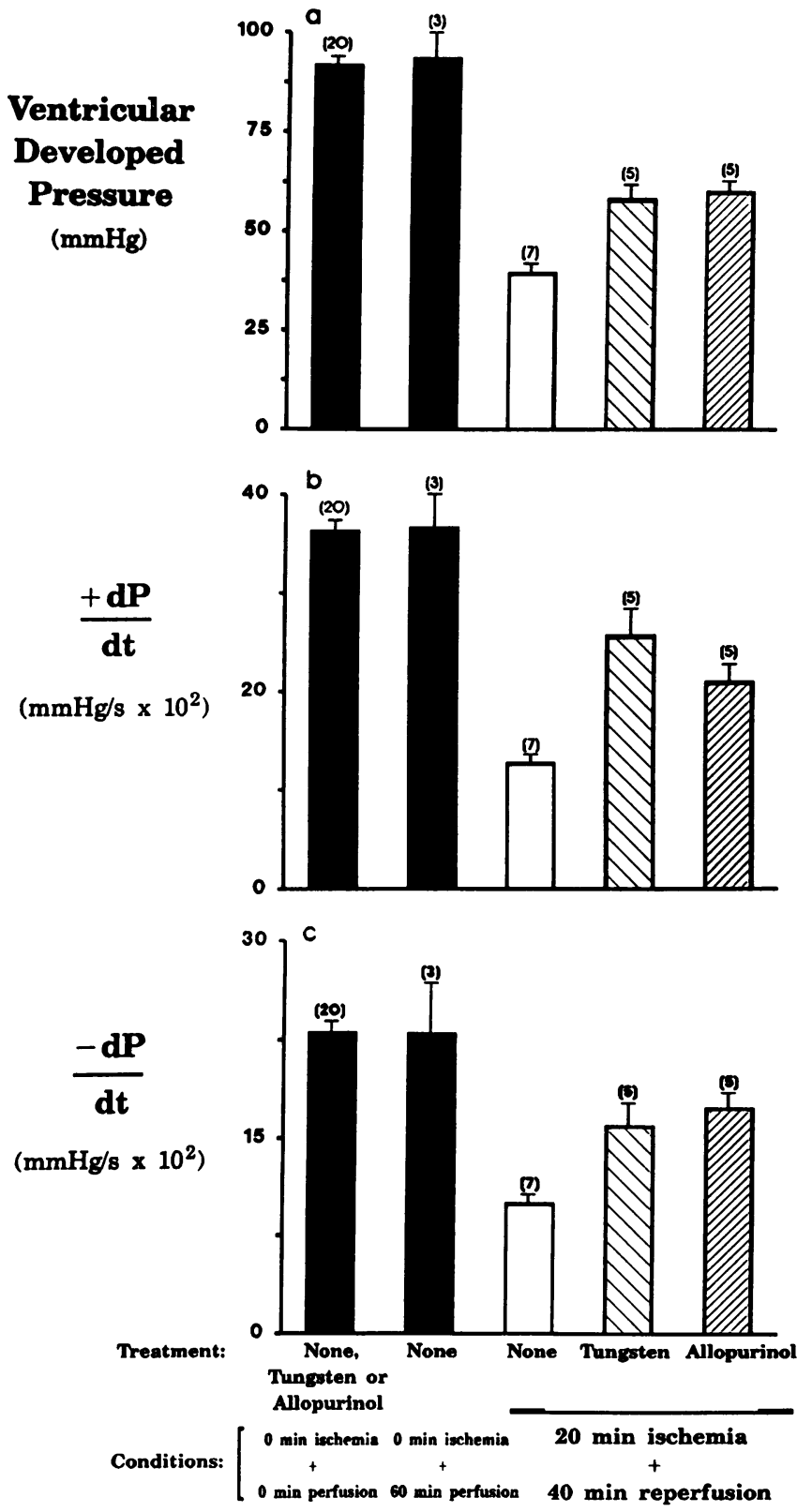

reperfusion for $40 \mathrm{~min}$, catalase activities were decreased $(P$ $<0.05$ ) in untreated or urea-treated hearts compared with DMTU-, tungsten-, or allopurinol-treated hearts.

\section{Discussion}

Our results provide evidence that $\mathrm{H}_{2} \mathrm{O}_{2}$ is generated during reperfusion of ischemic, isolated, perfused rat hearts. Specifically, we found that catalase activities decreased in hearts from aminotriazole-treated rats during reperfusion after ischemia, but not in hearts subjected to ischemia without reperfusion or perfusion without ischemia. Since aminotriazole is highly specific for the first intermediate in the reaction of catalase with $\mathrm{H}_{2} \mathrm{O}_{2}$ (compound I), assessing $\mathrm{H}_{2} \mathrm{O}_{2}$-mediated inactivation of catalase reflects $\mathrm{H}_{2} \mathrm{O}_{2}$ generation in biological systems $(11-13)$. Moreover, addition of DMTU only during reperfusion not only prevented decreases in cardiac function, but also prevented $\mathrm{H}_{2} \mathrm{O}_{2}$-dependent decreases in myocardial catalase activity after reperfusion of ischemic hearts. Although DMTU can react with $\mathrm{H}_{2} \mathrm{O}_{2}$, hydroxyl radical $(\cdot \mathrm{OH})$, or hypochlorous acid $(\mathrm{HOCl})$ in vitro $(6,17)$, the additional finding that DMTU decreased $\mathrm{H}_{2} \mathrm{O}_{2}$-mediated inactivation of catalase in hearts from aminotriazole-treated rats further suggests that $\mathrm{H}_{2} \mathrm{O}_{2}$ participates in cardiac reperfusion injury. Moreover, $\cdot \mathrm{OH}$ is usually generated from $\mathrm{H}_{2} \mathrm{O}_{2}$ in vivo (3); a contribution from $\mathrm{HOCl}$ seems unlikely since production of $\mathrm{HOCl}$ from $\mathrm{H}_{2} \mathrm{O}_{2}$

Figure 3. Ventricular function after global normothermic ischemia for $20 \mathrm{~min}$ and reperfusion for $\mathbf{4 0} \mathrm{min}$. (a) Ventricular DP, (b) contractility $(+\mathrm{d} P / \mathrm{d} t)$, and $(c)$ relaxation rate $(-\mathrm{d} P / \mathrm{d} t)$ measurements were the same $(P>0.05)$ in all hearts (untreated, tungsten, or allopurinol treated) studied before ischemia. In addition, perfusion for 60 min without ischemia did not change $(P>0.05) \mathrm{DP},+\mathrm{d} P / \mathrm{d} t$, or $-\mathrm{d} P / \mathrm{d} t$ from values obtained for hearts studied before ischemia.


hearts had decreased $(P<0.05) \mathrm{DP},+\mathrm{d} P / \mathrm{d} t$, or $-\mathrm{d} P / \mathrm{d} t$ values compared with values obtained for hearts studied before ischemia or hearts perfused for $60 \mathrm{~min}$ without ischemia. In contrast, after ischemia for $\mathbf{2 0 ~ m i n ~ a n d ~ r e p e r f u s i o n ~ f o r ~} \mathbf{4 0 ~ m i n , ~ h e a r t s ~ f r o m ~ r a t s ~ t h a t ~}$ had been pretreated with tungsten or allopurinol had increased $(P$ $<0.05) \mathrm{DP},+\mathrm{d} P / \mathrm{d} t$, and $-\mathrm{d} P / \mathrm{d} t$ compared with hearts from rats that received no treatment. Each bar is the mean \pm 1 SE of the number of determinations shown within the parentheses. 


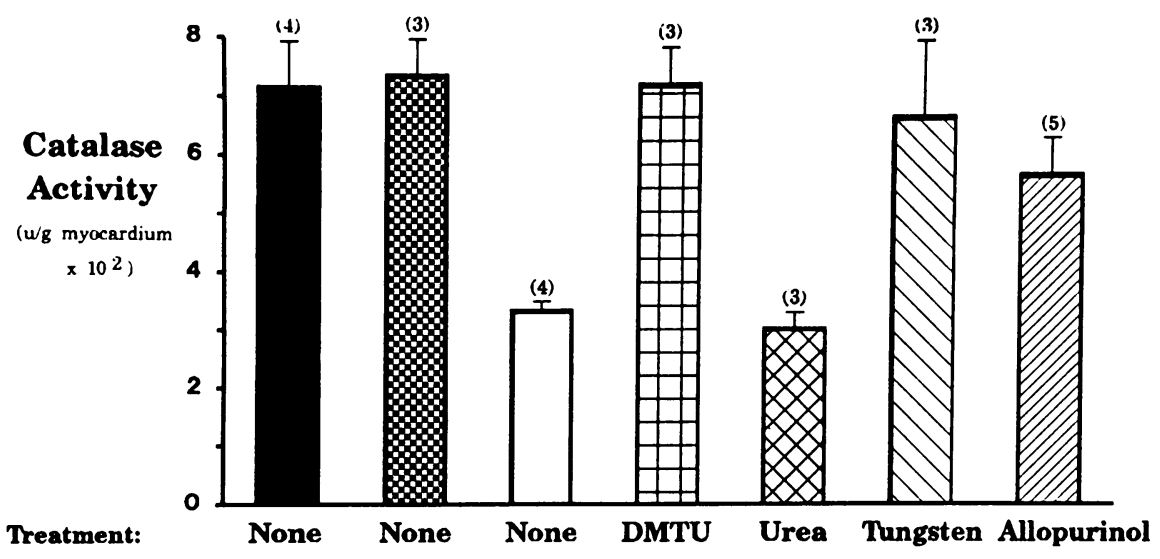

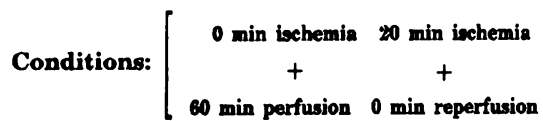

$20 \mathrm{~min}$ ischemia

$+$
Figure 4. Myocardial catalase activities measured after ischemia and reperfusion in rats pretreated with aminotriazole (Units per gram myocardium $\left.\times 10^{2}\right)$. Myocardial catalase levels were the same $(P>0.05)$ in hearts perfused for $60 \mathrm{~min}$ without ischemia or hearts subjected to ischemia for 20 min without reperfusion. However, catalase activities were less $(P<0.05)$ in hearts subjected to ischemia for $20 \mathrm{~min}$ and then reperfusion for $40 \mathrm{~min}$ than in hearts studied after perfusion for $60 \mathrm{~min}$ without ischemia or after ischemia for $20 \mathrm{~min}$ without reperfusion. In contrast, after ischemia for $20 \mathrm{~min}$ and reperfusion for $40 \mathrm{~min}$, hearts treated with DMTU simultaneously with reperfusion had catalase activities that were increased $(P<0.05)$ compared with untreated or urea-treated hearts. Similarly, after ischemia for $20 \mathrm{~min}$ and reperfusion for $40 \mathrm{~min}$, hearts from rats that had been treated with tungsten or allopurinol had

catalase activities which were increased $(P<0.05)$ compared with levels found in untreated hearts. Moreover, after ischemia for 20 min and reperfusion for $40 \mathrm{~min}$, catalase activities were the same $(P>0.05)$ in DMTU-, tungsten-, or allopurinol-treated hearts compared with hearts subjected to perfusion for $60 \mathrm{~min}$ without ischemia or ischemia for $20 \mathrm{~min}$ without reperfusion. Each bar is the mean $\pm 1 \mathrm{SE}$ of the number of determinations shown within the parentheses.

requires neutrophil myeloperoxidase (18) and essentially no neutrophils are present in the isolated Krebs-Henseleit perfused heart. Thus, our findings suggest that $\mathrm{H}_{2} \mathrm{O}_{2}$ is made during reperfusion and that $\mathrm{H}_{2} \mathrm{O}_{2}$ contributes either directly or indirectly to the development of cardiac dysfunction after ischemia.

Our study also indicates that $\mathrm{XO}$ generates $\mathrm{H}_{2} \mathrm{O}_{2}$ during reperfusion of ischemic rat hearts. Parallel decreases in myocardial XO activity, ventricular dysfunction, and $\mathrm{H}_{2} \mathrm{O}_{2}$ generation occurred in tungsten- or allopurinol-treated rats subjected to ischemia and then reperfusion. Tungsten is a relatively specific inhibitor that inactivates xanthine, aldehyde, and sulfite oxidases by interfering with their molybdenum-dependent active site (7-9). By comparison, allopurinol and its metabolite oxipurinol are potent, specific competitive inhibitors of $\mathrm{XO}$ (10), but not sulfite or aldehyde oxidases. Accordingly, measurable inhibition of $\mathrm{XO}$ by either tungsten or allopurinol treatment, in conjunction with improved function and lessened myocardial $\mathrm{H}_{2} \mathrm{O}_{2}$ generation, focuses on $\mathrm{XO}$ as the predominant source of $\mathrm{H}_{2} \mathrm{O}_{2}$ production during reperfusion after ischemia. Furthermore, because isolated hearts contain virtually no circulating blood elements, participation of $\mathrm{O}_{2}$ metabolites from neutrophils, platelets, or other blood sources is unlikely.

Finally, DMTU, tungsten, or allopurinol treatment prevented $\mathrm{H}_{2} \mathrm{O}_{2}$-dependent decreases in catalase after reperfusion, but did not completely eradicate ventricular dysfunction after reperfusion. Thus, cardiac dysfunction following reperfusion after ischemia may also depend on mechanisms that are independent of processes involving $\mathrm{H}_{2} \mathrm{O}_{2}$ made by $\mathrm{XO}$.

\section{Acknowledgments}

The authors acknowledge the excellent assistance of Jacqueline Borenstein in preparing this manuscript. The authors also appreciate the valuable advice of Darrell N. Jones, Ph.D.
This work was supported in part by grants from the National Institutes of Health (P01-AM 35098, R01-HL 35378, R01-HL 28182, P01-HL 27353, and R01-HL 34486); the American Heart Association; the Council for Tobacco Research Inc.; and the Swan, Hill, American Express, and Johnson and Johnson Foundations. Dr. Brown is a Fellow of the American Heart Association.

\section{References}

1. Braunwald, E., and R. A. Kloner. 1985. Myocardial reperfusion: a double edged sword? J. Clin. Invest. 76:1713-1719.

2. Buckberg, G. D. 1986. Studies of controlled reperfusion after ischemia. J. Thorac. Cardiovasc. Surg. 92:1-648.

3. Cross, C. W., B. Halliwell, E. T. Borish, M. A. Pryor, B. N. Amen, R. L. Saul, J. M. McCord, and D. Harwan. 1987. Oxygen radicals and human disease. Ann. Intern. Med. 107:526-545.

4. McCord, J. M. 1985. Oxygen derived free radicals in postischemic tissue injury. N. Engl. J. Med. 312:159-163.

5. Rodell, T. C., J. C. Cheronis, and J. E. Repine. 1987. Xanthine oxidase mediates elastase induced injury to isolated lungs and endothelium. J. Appl. Physiol. 63:2159-2163.

6. Jackson, J. H., C. W. White, N. B. Parker, J. W. Ryan, and J. E. Repine. 1985. Dimethylthiourea consumption reflects $\mathrm{H}_{2} \mathrm{O}_{2}$ concentration and severity of acute lung injury. J. Appl. Physiol. 59:19951998.

7. Renzo, E. C. 1954. Studies on the nature of the xanthine oxidase factor. Ann. NY Acad. Sci. 57:905-908.

8. Higgins, E. G., D. A. Richert, and W. W. Westerfeld. 1956. Molybdenum deficiency and tungstate inhibition studies. J. Nutr. 59:539-559.

9. Johnson, J. L., K. V. Rajagopalan, and H. J. Cohen. 1974. Molecular basis of the biological function of molybdenum. J. Biol. Chem. 249:859-866.

10. Parks, D. A., and N. D. Granger. 1986. Xanthine oxidase: biochemistry, distribution and physiology. Acta Physiol. Scand. 548:87-99.

11. Feinstein, R. N., S. Berliner, and F. O. Green. 1958. Mecha- 
nism of inhibition of catalase by 3-amino-1,2,4-triazole. Arch. Biochem. Biophys. 76:32-44.

12. Cohen, G., and N. L. Somerson. 1969. Catalase-aminotriazole method for measuring secretion of hydrogen peroxide by microorganisms. J. Bacteriol. 98:543-546.

13. Doring, H. J., and H. Dehvert. 1986. The isolated perfused warm-blooded heart according to Langendorff. In Biological Measurement Techniques. Vol. 5. 1-107.

14. Patt, A., A. H. Harken, L. K. Burton, T. C. Rodell, D. Piermatter, W. J. Schorr, N. B. Parker, E. M. Berger, I. R. Horesh, L. S. Terada, S. L. Linas, J. C. Cheronis, and J. E. Repine. 1988. Xanthine oxidase-derived hydrogen peroxide contributes to ischemia-reperfusion induced edema in gerbil brains. J. Clin. Invest. 81:5.
15. Schoutsen, B., J. W. D. Jong, E. Harmsen, and D. W. Achterberg. 1983. Myocardial xanthine oxidase/dehydrogenase. Biochim. Biophys. Acta. 762:519-524.

16. Worcestor, J. 1966. The statistical method. N. Engl. J. Med. 274:27-36.

17. Wasil, M., B. Halliwell, M. Grootveld, C. P. Moorhouse, D. C. S. Hutchinson, and H. Bum. 1987. The specificity of thiourea, dimethylthiourea and dimethyl sulfoxide as scavengers of hydroxyl radicals. Their protection of alpha-1-antiprotease against inactivation by hypochlorous acid. Biochem. J. 243:867-870.

18. Weiss, S. J., R. Klein, A. Slivka, and M. Wei. 1982. Chlorination of taurine by human neutrophils. Evidence for hypochlorous acid generation. J. Clin. Invest. 70:598-607. 